\title{
10. CARBON-CARBONATE CONTENT OF SEDIMENTS FROM THE WESTERN EQUATORIAL PACIFIC: LEG 7, GLOMAR CHALLENGER
}

\author{
E. L. Gealy, Scripps Institution of Oceanography, University of California, \\ La Jolla, California
}

\begin{abstract}
A 2 to 3 cubic centimeter sample of sediment was taken aboard ship from each section recovered on Leg 7 for determination of carbon and carbonate content, and analyses were made on shore. This report reviews the techniques and presents the results of those analyses.
\end{abstract}

All of the analyses were made on a LECO 70 Second Carbon Analyzer, and details of the procedures used are set forth in Appendix III of Volume IV of the Initial Reports of the Deep Sea Drilling Project (1970).

In general, each sample is pulverized, dried, split and weighed. One part (about 0.1 gram) of the sample is processed, untreated, in the LECO 70 Analyzer, and the percentage of total carbon is obtained by dividing a calibrated digital readout by the sample weight. The second part (about 0.5 gram) of the sample is treated with hydrochloric acid to remove the carbonate, washed, dried and processed in the LECO 70 Analyzer. The percentage of organic carbon is calculated by dividing the calibrated digital readout by the sample weight. Carbonate percentage is determined, assuming that all carbonate is calcium carbonate:

$$
\begin{aligned}
\text { Per cent carbonate }= & \begin{aligned}
(\% \text { total carbon }-\% \text { organic } \\
\text { carbon })
\end{aligned} 8.33
\end{aligned}
$$

Where the sample is known to contain dolomite, the carbonate percentage must be adjusted:

Per cent $\mathrm{CaMg}\left(\mathrm{CO}_{3}\right) 2=\left[\% \mathrm{Ca}\left(\mathrm{CO}_{3}\right) 2\right] \frac{15.02}{8.33}$

For rhodochrosite, the percentage of carbonate must be adjusted:

$$
\text { Per cent } \mathrm{MnCO}_{3}=\left[\% \mathrm{CA}\left(\mathrm{CO}_{3}\right) 2\right] \frac{9.57}{8.33}
$$

The carbonate percentage is shown as a function of depth on the core description charts and Site Summaries in Chapters 3 through 9; total carbon, percentage of organic carbon and of carbonate are listed in Table 3 of this chapter, and selected values are listed in the tables of physical and chemical properties in Chapters 3 through 9 .

Because of errors inherent in the analytical process, a few of the values derived for both carbonate and organic carbon are impossible, and were handled as follows: All values $<-0.3$ per cent were considered to be erroneous and were omitted. Values -0.3 to 0.0 per cent were called 0.0 . Values $>110$ per cent were considered to be erroneous and were omitted. Values 100 to 110 per cent were called 100 per cent.

After samples taken on Leg 7 were analyzed for carbon-carbonate, selected duplicate samples from Leg 7 and other legs were analyzed by R. E. Boyce of the Deep Sea Drilling Project, using the LECO 70 acid-base method under carefully controlled conditions. The acid-base method will be presented in detail, together with comparison of results by the LECO 70 and acid-base techniques for Leg 7 and earlier legs, probably in Volume IX of the Initial Reports of the Deep Sea Drilling Project.

Mr. Boyce states that analyses by the acid-base method yield data with the following precision:

Total carbon

$(1.2$ to 12.0 per cent by weight $)= \pm 0.3 \%$ absolute

( 0 to 1.2 per cent by weight $)= \pm 0.06 \%$ absolute

Organic carbon $= \pm 0.05 \%$ absolute

Calcium carbonate

(10 to 100 per cent by weight $)= \pm 2.5 \%$ absolute

( 0 to 10 per cent by weight) $= \pm 0.5 \%$ absolute

In the acid-base technique, each sample is pulverized, dried, split and weighed, as in the LECO 70 technique. One-half is analyzed intact; one-half is acidified to remove the carbonate. Samples are burned at $1600^{\circ} \mathrm{C}$ in a LECO carbon furnace. The volume of the liberated gas (commonly carbon dioxide and oxygen) is measured in a solution of dilute sulfuric acid and methyl orange. The gas is passed through a potassiumhydroxide solution which preferentially absorbs carbon dioxide, and the volume of the effluent gas is measured. The difference between the two gas volumes is the volume of carbon dioxide.

Comparison of measurements by the two methods indicates that the LECO 70 second technique renders values of carbon contents that are too low (Table 1, Figure 1), and the percentage error appears to increase with increased carbon content. 
TABLE 1

Comparison of Values of Total Carbon, Organic Carbon and Carbonate Obtained by LECO 70 and Acid Base Methods; Samples from Leg 7

\begin{tabular}{|c|c|c|c|c|c|c|c|c|c|c|c|c|c|}
\hline \multirow[b]{2}{*}{ Hole } & \multirow[b]{2}{*}{ Core } & \multirow[b]{2}{*}{ Section } & \multicolumn{2}{|c|}{ Interval from Top } & \multicolumn{3}{|c|}{ Total Carbon (\% wt.) } & \multicolumn{3}{|c|}{ Organic Carbon (\% wt.) } & \multicolumn{3}{|c|}{$\mathrm{CaCO}_{3}$ Per Cent wt. } \\
\hline & & & $\begin{array}{c}\mathrm{C}_{\mathrm{T}^{\prime}} \\
\text { (LECO 70) }\end{array}$ & $\begin{array}{c}\mathrm{C}_{\mathrm{T}} \text { (Acid } \\
\text { Base })\end{array}$ & $\begin{array}{c}\text { LECO } \\
70\end{array}$ & $\begin{array}{l}\text { Acid } \\
\text { Base }\end{array}$ & $\begin{array}{c}\Delta_{\mathrm{T}}= \\
\mathrm{C}_{\mathrm{T}}-\mathrm{C}_{\mathrm{T}^{\prime}}\end{array}$ & $\begin{array}{c}\mathrm{C}_{\mathrm{O}^{\prime}} \\
\text { (LECO 70) }\end{array}$ & $\begin{array}{c}\mathrm{C}_{\mathrm{O}} \\
\text { (Acid } \\
\text { Base) }\end{array}$ & $\begin{array}{c}\Delta_{O}= \\
\mathrm{C}_{\mathrm{O}^{-}}-\mathrm{C}_{\mathrm{O}^{\prime}}\end{array}$ & $\begin{array}{c}\left(\mathrm{CO}_{3}\right)^{\prime} \\
(\text { LECO } 70) \\
\end{array}$ & $\begin{array}{l}\left(\mathrm{CO}_{3}\right)^{\prime} \\
\text { Acid } \\
\text { Base }\end{array}$ & $\begin{array}{c}\Delta=\left(\mathrm{CO}_{3}\right) \\
-\left(\mathrm{CO}_{3}\right)\end{array}$ \\
\hline 61.1 & 1 & 2 & & 69 & 0.000 & 0.227 & 0.227 & & & & & & \\
\hline 62.0 & 1 & 2 & & 20 & 9.880 & 9.990 & 0.110 & & & & & & \\
\hline 62.0 & 4 & 2 & 20 & 20 & 10.286 & 10.200 & -0.086 & 0.000 & 0.1 & 0.100 & 85.680 & 84.3 & -1.380 \\
\hline 62.0 & 5 & 3 & 20 & 20 & 10.640 & 11.500 & 0.860 & 0.000 & 0.1 & 0.100 & 88.631 & 94.6 & 5.696 \\
\hline 62.1 & 1 & 2 & 50 & 50 & 7.760 & 8.900 & 1.140 & 0.307 & 0.3 & -0.007 & 62.086 & 71.8 & 9.714 \\
\hline 62.1 & 10 & 3 & 22 & 22 & 7.960 & 8.800 & 0.840 & 0.094 & 0.2 & 0.106 & 65.526 & 72.1 & 6.574 \\
\hline 62.1 & 14 & 1 & 89 & 89 & 10.450 & 10.900 & 0.450 & 0.144 & 0.1 & -0.044 & 85.851 & 89.3 & 3.449 \\
\hline 62.1 & 15 & 5 & & 20 & 8.120 & 11.080 & 2.960 & & & & & & \\
\hline 62.1 & 19 & 3 & 20 & 20 & 11.560 & 11.200 & -0.360 & 0.040 & 0.1 & 0.060 & 95.962 & 92.7 & -3.262 \\
\hline 62.1 & 36 & 5 & & 20 & 10.267 & 10.590 & 0.323 & & & & & & \\
\hline 63.0 & 1 & 2 & 21 & 16 & 1.130 & 1.100 & -0.300 & 0.168 & 0.2 & 0.032 & 8.011 & 7.7 & -0.3110 \\
\hline 63.0 & 1 & 4 & & 20 & 1.664 & 2.050 & 0.386 & & & & & & \\
\hline 63.0 & 2 & 2 & 21 & 20 & 8.040 & 9.100 & 1.060 & 0.000 & 0.1 & 0.100 & 66.973 & 75.1 & 8.127 \\
\hline 63.0 & 3 & 1 & 61 & 60 & 8.640 & 10.200 & 1.560 & 0.000 & 0.1 & 0.100 & 71.971 & 84.4 & 12.429 \\
\hline 63.0 & 4 & 1 & 21 & 20 & 9.176 & 10.800 & 1.624 & 0.000 & 0.1 & 0.100 & 74.440 & 89.6 & 15.160 \\
\hline 63.0 & 5 & 1 & 36 & 35 & 9.200 & 10.800 & 1.600 & 0.000 & 0.1 & 0.100 & 76.636 & 89.3 & 12.664 \\
\hline 63.0 & 6 & 1 & 26 & 40 & 10.640 & 11.600 & 0.960 & 0.000 & 0.1 & 0.100 & 88.631 & 95.8 & 7.169 \\
\hline 63.0 & 6 & 2 & 21 & 21 & 10.880 & 11.800 & 0.920 & 0.000 & 0.1 & 0.100 & 90.630 & 97.9 & 7.270 \\
\hline 63.0 & 9 & 1 & 21 & 21 & 10.960 & 11.300 & 0.340 & 0.000 & 0.1 & 0.100 & 91.297 & 93.8 & 2.503 \\
\hline 63.2 & 3 & 3 & & 20 & 6.400 & 7.220 & 0.820 & & & & & & \\
\hline 64.0 & 1 & 1 & & 67 & 9.660 & 10.320 & 0.660 & & & & & & \\
\hline 64.0 & 1 & 2 & 110 & 110 & 9.640 & 9.600 & -0.040 & 0.000 & 0.2 & 0.200 & 80.301 & 78.3 & -2.001 \\
\hline 64.0 & 3 & 3 & 41 & 41 & 10.340 & 11.600 & 1.260 & 0.000 & 0.1 & 0.100 & 86.132 & 96.3 & 10.168 \\
\hline 64.0 & 6 & 5 & 20 & 20 & 9.120 & 10.300 & 1.180 & 0.080 & 0.1 & 0.020 & 75.303 & 85.1 & 9.797 \\
\hline 64.1 & 1 & 2 & & 25 & 9.640 & 11.420 & 1.780 & & & & & & \\
\hline 64.1 & 10 & 1 & 20 & 20 & 10.000 & 11.000 & 1.000 & 0.080 & 0.1 & 0.020 & 82.634 & 91.0 & 8.366 \\
\hline 64.1 & 10 & 2 & & 20 & 10.220 & 11.160 & 0.940 & & & & & & \\
\hline 65.0 & 14 & 5 & & 20 & 4.080 & 4.450 & 0.370 & & & & & & \\
\hline 65.1 & 5 & 2 & & 20 & 0.150 & 0.313 & 0.163 & & & & & & \\
\hline $\begin{array}{r}66.0 \\
(\mathrm{Sa}\end{array}$ & $\begin{array}{r}2 \\
\text { mple }\end{array}$ & 2 & 102 & 105 & 1.182 & 0.800 & -0.382 & 0.173 & 0.1 & -0.073 & 8.402 & 5.5 & -2.902 \\
\hline $\begin{array}{r}66.0 \\
(\mathrm{~S} .\end{array}$ & $\begin{array}{r}2 \\
\text { ample }\end{array}$ & 2 & & 102 & 1.182 & 1.320 & 138 & & & & & & \\
\hline 66.1 & 3 & 6 & & 18 & 0.260 & 0.701 & 0.441 & & & & & & \\
\hline 66.1 & 5 & 1 & & 30 & 0.184 & 0.426 & 0.242 & & & & & & \\
\hline 67.0 & 1 & 1 & & 34 & 0.172 & 0.380 & 0.208 & & & & & & \\
\hline
\end{tabular}




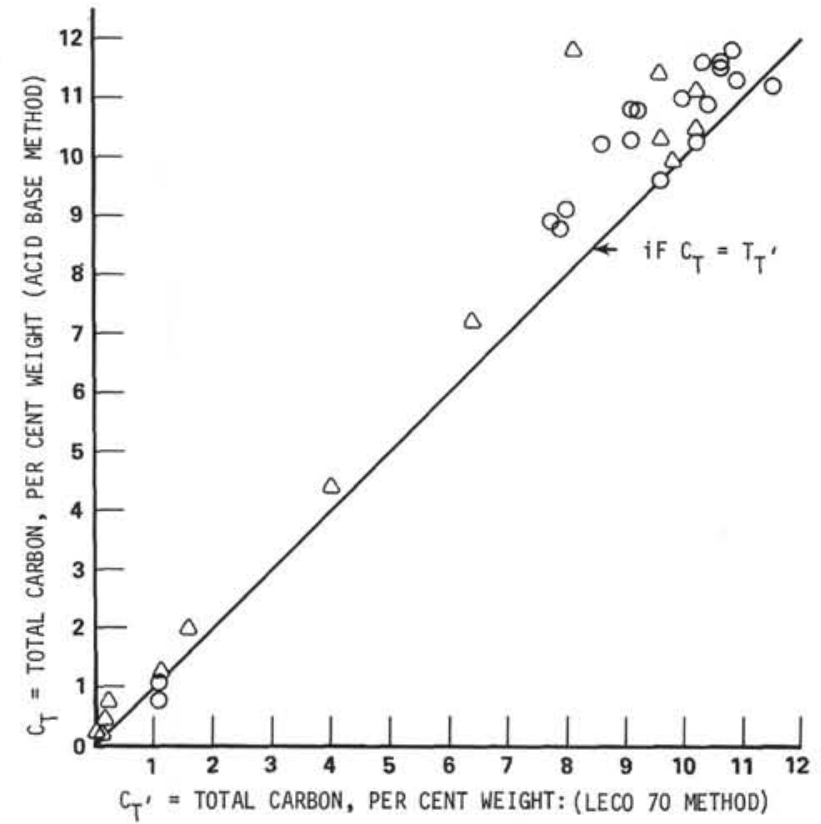

Figure 1. Comparison: Total Carbon, LECO 70 and Acid-Base Methods.

The scatter in the data is wide and no absolute correction factor can be applied. However, the values of total carbon and carbonate reported for this leg are probably low by amounts listed in Table 2 .

\section{CARBONATE RESULTS}

\section{Site 61}

Analyses of two samples from Site 61 (61.1-1-1 and 61.1-1-2) showed no measurable carbon content.

\section{Site 62}

The nannofossil ooze-chalk-limestone sequence penetrated at Site 62 is carbonate-rich. Few samples contain less than 60 per cent calcium carbonate; most contain more than 80 per cent calcium carbonate. Near surface samples are most poor in carbonate. The Quaternary changes from a nannofossil marl (57 to 62 per cent carbonate) near the surface to a nannofossil ooze (71 to 80 per cent carbonate) at 40 meters. There is a steady increase in carbonate content with depth throughout the Pliocene and Late Miocene materials to a depth of 190 meters, where the carbonate content exceeds 90 per cent in most samples. This zone of maximum carbonate coincides with the zone rich in foraminifera. From 90 per cent at 190 meters, the carbonate content decreases steadily to about 80 per cent at 280 meters (Middle-Late Miocene), then increases to 90 per cent at 300 meters, and decreases again to about 80 per cent at 400 meters (Early and Middle Miocene).
TABLE 2

Estimated Correction Factors, Measurements of Total Carbon and Carbonate by LECO 70 Method, Leg 7

\begin{tabular}{cc}
\hline $\begin{array}{c}\text { Values Total Carbon by } \\
\text { LECO } 70 \text { (This Volume) }\end{array}$ & $\begin{array}{c}\text { Estimated Correction } \\
\text { Factor }\end{array}$ \\
\hline $12 \%$ & +0 to $2.2 \%$ \\
$10 \%$ & +0 to $1.8 \%$ \\
$8 \%$ & +0 to $1.6 \%$ \\
$6 \%$ & +0 to $1.2 \%$ \\
$4 \%$ & +0 to $0.9 \%$ \\
$2 \%$ & +0 to $0.6 \%$ \\
$0 \%$ & +0 to $0.3 \%$ \\
$100 \%$ & +0 to $13.0 \%$ \\
$90 \%$ & +0 to $12.0 \%$ \\
$80 \%$ & +0 to $11.0 \%$ \\
$70 \%$ & +0 to $9.0 \%$ \\
$60 \%$ & +0 to $8.0 \%$ \\
$50 \%$ & +0 to $7.0 \%$ \\
$40 \%$ & +0 to $5.0 \%$ \\
$30 \%$ & +0 to $4.0 \%$ \\
$20 \%$ & +0 to $3.0 \%$ \\
$10 \%$ & +0 to $1.0 \%$ \\
\hline
\end{tabular}

The carbon content of the dolomite recovered from Core 62.0-7 was not determined.

Most of the section penetrated is devoid of organic carbon in amounts detectable by techniques used. However, at the surface and at several intervals in the hole, organic carbon was detected in amounts ranging up to 1.3 per cent (Table 1). The deepest sample in which organic carbon was detected was from Cores 62.0-4, 5 and 6, in an Early Miocene nannofossil chalk. The presence of pyrite throughout the ooze-chalk sequence at this site infers a reducing condition which would permit the preservation of organic debris.

\section{Site 63}

The upper 35 to 60 meters of the section penetrated at Site 63 is a Pliocene sequence of alternating clays, marls and calcareous oozes. The carbonate content increases irregularly from only 4 per cent at the surface to about 80 per cent in the Late Miocene ooze at 60 meters. The carbonate content is lower in the Middle Miocene at 100 to 130 meters (about 50 per cent), below which it appears to increase steadily with depth 
TABLE 3

Carbon-Carbonate Results: Leg 7, Glomar Challenger

\begin{tabular}{|c|c|c|c|c|c|c|c|}
\hline Hole & Core & Section & $\begin{array}{l}\text { Top } \\
\text { Interval }\end{array}$ & Lithology & $\begin{array}{c}\text { Total } \\
\text { Carbon } \\
\text { (\% wt.) }\end{array}$ & $\begin{array}{l}\text { Organic } \\
\text { Carbon } \\
\text { (\% wt.) } \\
\end{array}$ & $\begin{array}{c}\text { Calcium } \\
\text { Carbonate } \\
\text { (\% wt.) }\end{array}$ \\
\hline 61.1 & 1 & 1 & 120.0 & $\begin{array}{l}\text { Porcelanite, mudstone, shale } \\
\text { and siltstone }\end{array}$ & 0.0 & 0.03 & 0.0 \\
\hline 61.1 & 1 & 2 & 69.0 & $\begin{array}{l}\text { Porcelanite, mudstone, shale } \\
\text { and siltstone }\end{array}$ & 0.0 & 0.00 & 0.0 \\
\hline 62.0 & 1 & 1 & 20.0 & Nannofossil chalk ooze & 10.2 & 0.00 & 84.8 \\
\hline 62.0 & 1 & 2 & 20.0 & Nannofossil chalk ooze & 9.9 & 0.00 & 82.3 \\
\hline 62.0 & 1 & 3 & 20.0 & Nannofossil chalk ooze & 10.5 & 0.00 & 87.5 \\
\hline 62.0 & 1 & 4 & 20.0 & Nannofossil chalk ooze & 10.2 & 0.00 & 84.8 \\
\hline 62.0 & 1 & 5 & 20.0 & Nannofossil chalk ooze & 9.5 & 0.00 & 79.3 \\
\hline 62.0 & 1 & 6 & 20.0 & Nannofossil chalk ooze & 10.3 & 0.00 & 85.6 \\
\hline 62.0 & 2 & 1 & 110.0 & Nannofossil chalk ooze & 10.7 & 0.00 & 89.5 \\
\hline 62.0 & 2 & 2 & 25.0 & Nannofossil chalk ooze & 10.8 & 0.00 & 89.6 \\
\hline 62.0 & 2 & 3 & 24.0 & Nannofossil chalk ooze & 10.4 & 0.00 & 87.0 \\
\hline 62.0 & 2 & 4 & 25.0 & Nannofossil chalk ooze & 10.7 & 0.00 & 89.5 \\
\hline 62.0 & 2 & 5 & 20.0 & Nannofossil chalk ooze & 10.9 & 0.01 & 90.9 \\
\hline 62.0 & 2 & 6 & 20.0 & Nannofossil chalk ooze & 11.3 & 0.00 & 93.8 \\
\hline 62.0 & 3 & 1 & 34.0 & Nannofossil chalk ooze & 10.9 & 0.00 & 91.0 \\
\hline 62.0 & 3 & 2 & 20.0 & Nannofossil chalk ooze & 11.6 & 0.00 & 97.0 \\
\hline 62.0 & 3 & 3 & 20.0 & Nannofossil chalk ooze & 10.6 & 0.00 & 88.6 \\
\hline 62.0 & 3 & 4 & 20.0 & Nannofossil chalk ooze & 10.9 & 0.00 & 90.8 \\
\hline 62.0 & 3 & 5 & 20.0 & Nannofossil chalk ooze & 11.3 & 0.00 & 94.0 \\
\hline 62.0 & 3 & 6 & 20.0 & Nannofossil chalk ooze & 10.6 & 0.00 & 88.3 \\
\hline 62.0 & 4 & 1 & 5.0 & Nannofossil chalk ooze \& chalk & 9.4 & 0.00 & 78.3 \\
\hline 62.0 & 4 & 2 & 20.0 & Nannofossil chalk ooze \& chalk & 10.3 & 0.00 & 85.7 \\
\hline 62.0 & 4 & 3 & 20.0 & Nannofossil chalk ooze \& chalk & 9.9 & 0.00 & 82.8 \\
\hline 62.0 & 4 & 4 & 20.0 & Nannofossil chalk ooze \& chalk & 9.7 & 0.00 & 81.0 \\
\hline 62.0 & 4 & 5 & 20.0 & Nannofossil chalk ooze \& chalk & 10.0 & 0.01 & 83.5 \\
\hline 62.0 & 4 & 6 & 20.0 & Nannofossil chalk ooze \& chalk & 9.6 & 0.07 & 79.7 \\
\hline 62.0 & 5 & 2 & 20.0 & Nannofossil chalk ooze \& chalk & 10.7 & 0.00 & 89.1 \\
\hline 62.0 & 5 & 3 & 20.0 & Nannofossil chalk ooze \& chalk & 10.6 & 0.00 & 88.6 \\
\hline 62.0 & 5 & 4 & 20.0 & Nannofossil chalk ooze \& chalk & 11.1 & 0.00 & 92.7 \\
\hline 62.1 & 1 & 2 & 50.0 & $\begin{array}{l}\text { Foraminiferal nannofossil } \\
\text { chalk ooze }\end{array}$ & 7.8 & 0.31 & 62.1 \\
\hline 62.1 & 1 & 3 & 20.0 & $\begin{array}{l}\text { Foraminiferal nannofossil } \\
\text { chalk ooze }\end{array}$ & 7.0 & 0.25 & 56.5 \\
\hline 62.1 & 4 & 1 & 20.0 & Nannofossil chalk ooze & 8.7 & 0.00 & 72.2 \\
\hline 62.1 & 4 & 2 & 20.0 & Nannofossil chalk ooze & 8.5 & 0.00 & 71.0 \\
\hline 62.1 & 4 & 3 & 20.0 & Nannofossil chalk ooze & 9.0 & 0.00 & 75.1 \\
\hline 62.1 & 4 & 4 & 20.0 & Nannofossil chalk ooze & 9.6 & 0.00 & 79.8 \\
\hline
\end{tabular}


TABLE 3 - Continued

\begin{tabular}{|c|c|c|c|c|c|c|c|}
\hline Hole & Core & Section & $\begin{array}{c}\text { Top } \\
\text { Interval }\end{array}$ & Lithology & $\begin{array}{l}\text { Total } \\
\text { Carbon } \\
\text { (\% wt.) }\end{array}$ & $\begin{array}{l}\text { Organic } \\
\text { Carbon } \\
\text { (\% wt.) }\end{array}$ & $\begin{array}{c}\text { Calcium } \\
\text { Carbonate } \\
\text { (\% wt.) }\end{array}$ \\
\hline 62.1 & 4 & 5 & 20.0 & Nannofossil chalk ooze & 9.6 & 0.00 & 80.1 \\
\hline 62.1 & 4 & 6 & 20.0 & Nannofossil chalk ooze & 9.1 & 0.00 & 75.8 \\
\hline 62.1 & 6 & 1 & 20.0 & Nannofossil marl ooze & 6.0 & 0.00 & 50.1 \\
\hline 62.1 & 6 & 2 & 20.0 & Nannofossil chalk ooze & 9.7 & 0.00 & 81.0 \\
\hline 62.1 & 6 & 3 & 20.0 & Nannofossil chalk ooze & 8.8 & 0.00 & 73.6 \\
\hline 62.1 & 6 & 4 & 20.0 & Nannofossil marl ooze & 7.1 & 0.00 & 59.1 \\
\hline 62.1 & 6 & 5 & 20.0 & Nannofossil chalk ooze & 8.9 & 0.00 & 74.3 \\
\hline 62.1 & 9 & 2 & 20.0 & Nannofossil chalk ooze & 9.5 & 0.00 & 79.1 \\
\hline 62.1 & 9 & 3 & 20.0 & Nannofossil chalk ooze & 8.9 & 0.03 & 74.0 \\
\hline 62.1 & 9 & 4 & 20.0 & Nannofossil chalk ooze & 7.5 & 0.01 & 62.5 \\
\hline 62.1 & 10 & 1 & 20.0 & Nannofossil marl ooze & 5.8 & 0.11 & 47.8 \\
\hline 62.1 & 10 & 2 & 40.0 & Nannofossil chalk ooze & 9.2 & 0.05 & 76.0 \\
\hline 62.1 & 10 & 3 & 22.0 & Nannofossil chalk ooze & 8.0 & 0.09 & 65.5 \\
\hline 62.1 & 10 & 4 & 40.0 & Nannofossil chalk ooze & 9.4 & 0.17 & 76.9 \\
\hline 62.1 & 10 & 5 & 20.0 & Nannofossil chalk ooze & 8.8 & 0.09 & 72.5 \\
\hline 62.1 & 10 & 6 & 18.0 & Nannofossil chalk ooze & 9.3 & 0.08 & 77.0 \\
\hline 62.1 & 11 & 1 & 20.0 & Nannofossil chalk ooze & 9.5 & 0.11 & 78.5 \\
\hline 62.1 & 11 & 2 & 20.0 & Nannofossil chalk ooze & 9.6 & 0.21 & 78.5 \\
\hline 62.1 & 11 & 3 & 21.0 & Nannofossil chalk ooze & 9.6 & 0.09 & 79.2 \\
\hline 62.1 & 11 & 4 & 25.0 & Nannofossil chalk ooze & 8.4 & 0.09 & 68.9 \\
\hline 62.1 & 11 & 5 & 20.0 & Nannofossil chalk ooze & 9.3 & 0.03 & 76.9 \\
\hline 62.1 & 11 & 6 & 40.0 & Nannofossil chalk ooze & 9.4 & 0.11 & 77.6 \\
\hline 62.1 & 12 & 1 & 20.0 & Nannofossil chalk ooze & 9.6 & 0.13 & 78.9 \\
\hline 62.1 & 12 & 2 & 20.0 & Nannofossil chalk ooze & 10.2 & 0.12 & 83.6 \\
\hline 62.1 & 12 & 3 & 30.0 & Nannofossil chalk ooze & 10.1 & 0.05 & 84.0 \\
\hline 62.1 & 12 & 4 & 20.0 & Nannofossil chalk ooze & 10.1 & 0.06 & 83.5 \\
\hline 62.1 & 12 & 5 & 20.0 & Nannofossil chalk ooze & 10.0 & 0.11 & 82.4 \\
\hline 62.1 & 12 & 6 & 20.0 & Nannofossil chalk ooze & 10.4 & 0.05 & 86.2 \\
\hline 62.1 & 13 & 3 & 124.0 & Nannofossil chalk ooze & 9.5 & 0.07 & 78.7 \\
\hline 62.1 & 13 & 4 & 71.0 & Nannofossil chalk ooze & 10.4 & 0.12 & 85.8 \\
\hline 62.1 & 13 & 5 & 20.0 & Nannofossil chalk ooze & 10.2 & 0.12 & 84.0 \\
\hline 62.1 & 13 & 6 & 49.0 & Nannofossil chalk ooze & 10.6 & 0.22 & 86.3 \\
\hline 62.1 & 14 & 1 & 89.0 & Nannofossil chalk ooze & 10.4 & 0.14 & 85.9 \\
\hline 62.1 & 14 & 2 & 29.0 & Nannofossil chalk ooze & 10.3 & 0.15 & 84.5 \\
\hline 62.1 & 14 & 3 & 20.0 & Nannofossil chalk ooze & 10.4 & 0.00 & 86.6 \\
\hline 62.1 & 14 & 4 & 57.0 & Nannofossil chalk ooze & 9.3 & 0.00 & 77.8 \\
\hline 62.1 & 14 & 5 & 67.0 & Nannofossil chalk ooze & 10.3 & 0.00 & 85.6 \\
\hline 62.1 & 14 & 6 & 24.0 & Nannofossil chalk ooze & 10.1 & 0.00 & 84.3 \\
\hline 62.1 & 15 & 1 & 32.0 & Nannofossil marl ooze & 5.0 & 0.00 & 41.8 \\
\hline
\end{tabular}


TABLE 3 - Continued

\begin{tabular}{|c|c|c|c|c|c|c|c|}
\hline Hole & Core & Section & $\begin{array}{c}\text { Top } \\
\text { Interval }\end{array}$ & Lithology & $\begin{array}{l}\text { Total } \\
\text { Carbon } \\
\text { (\% wt.) }\end{array}$ & $\begin{array}{l}\text { Organic } \\
\text { Carbon } \\
(\% \text { wt. }) \\
\end{array}$ & $\begin{array}{c}\text { Calcium } \\
\text { Carbonate } \\
\text { (\% wt.) }\end{array}$ \\
\hline 62.1 & 15 & 2 & 20.0 & Nannofossil chalk ooze & 10.3 & 0.00 & 85.6 \\
\hline 62.1 & 15 & 3 & 20.0 & Nannofossil chalk ooze & 10.4 & 0.00 & 86.6 \\
\hline 62.1 & 15 & 4 & 20.0 & Nannofossil chalk ooze & 7.2 & 0.00 & 60.1 \\
\hline 62.1 & 15 & 5 & 20.0 & Nannofossil chalk ooze & 8.1 & 0.00 & 67.6 \\
\hline 62.1 & 15 & 6 & 20.0 & Nannofossil chalk ooze & 10.1 & 0.13 & 82.9 \\
\hline 62.1 & 16 & 1 & 20.0 & Nannofossil chalk ooze & 10.9 & 0.08 & 90.1 \\
\hline 62.1 & 16 & 2 & 40.0 & Nannofossil chalk ooze & 10.6 & 0.00 & 88.5 \\
\hline 62.1 & 16 & 3 & 20.0 & Nannofossil chalk ooze & 10.4 & 0.00 & 86.8 \\
\hline 62.1 & 16 & 4 & 20.0 & Nannofossil chalk ooze & 10.1 & 0.03 & 83.6 \\
\hline 62.1 & 16 & 5 & 21.0 & Nannofossil chalk ooze & 10.8 & 0.09 & 89.2 \\
\hline 62.1 & 16 & 6 & 20.0 & Nannofossil chalk ooze & 9.8 & 0.16 & 80.7 \\
\hline 62.1 & 17 & 1 & 136.0 & Nannofossil chalk ooze & 10.5 & 0.11 & 86.4 \\
\hline 62.1 & 17 & 2 & 20.0 & Nannofossil chalk ooze & 10.4 & 0.03 & 86.4 \\
\hline 62.1 & 17 & 3 & 20.0 & Nannofossil chalk ooze & 11.7 & 0.00 & 97.3 \\
\hline 62.1 & 17 & 4 & 20.0 & Nannofossil chalk ooze & 10.8 & 0.00 & 89.7 \\
\hline 62.1 & 17 & 5 & 20.0 & Nannofossil chalk ooze & 11.3 & 0.15 & 93.0 \\
\hline 62.1 & 17 & 6 & 20.0 & Nannofossil chalk ooze & 10.2 & 0.21 & 83.2 \\
\hline 62.1 & 18 & 1 & 20.0 & Nannofossil chalk ooze & 10.6 & 0.07 & 88.0 \\
\hline 62.1 & 18 & 2 & 20.0 & Nannofossil chalk ooze & 10.9 & 0.01 & 91.1 \\
\hline 62.1 & 18 & 3 & 20.0 & Nannofossil chalk ooze & 11.3 & 0.05 & 94.0 \\
\hline 62.1 & 18 & 4 & 20.0 & Nannofossil chalk ooze & 11.2 & 0.00 & 93.5 \\
\hline 62.1 & 18 & 5 & 20.0 & Nannofossil chalk ooze & 10.6 & 0.03 & 87.9 \\
\hline 62.1 & 18 & 6 & 17.0 & Nannofossil chalk ooze & 10.7 & 0.00 & 88.8 \\
\hline 62.1 & 19 & 1 & 85.0 & Nannofossil chalk ooze & 11.1 & 0.05 & 91.7 \\
\hline 62.1 & 19 & 2 & 90.0 & Nannofossil chalk ooze & 11.4 & 0.05 & 94.6 \\
\hline 62.1 & 19 & 3 & 20.0 & Nannofossil chalk ooze & 11.6 & 0.04 & 96.0 \\
\hline 62.1 & 19 & 4 & 20.0 & Nannofossil chalk ooze & 11.1 & 0.05 & 92.4 \\
\hline 62.1 & 19 & 5 & 20.0 & Nannofossil chalk ooze & 11.0 & 0.00 & 92.0 \\
\hline 62.1 & 19 & 6 & 23.0 & Nannofossil chalk ooze & 7.4 & 0.00 & 62.0 \\
\hline 62.1 & 20 & 1 & 20.0 & Nannofossil chalk ooze & 10.9 & 0.04 & 90.8 \\
\hline 62.1 & 20 & 2 & 20.0 & Nannofossil chalk ooze & 10.8 & 0.00 & 89.6 \\
\hline 62.1 & 20 & 2 & 20.0 & Nannofossil chalk ooze & 8.8 & 0.01 & 73.0 \\
\hline 62.1 & 20 & 3 & 20.0 & Nannofossil chalk ooze & 11.2 & 0.02 & 93.1 \\
\hline 62.1 & 20 & 4 & 20.0 & Nannofossil chalk ooze & 10.9 & 0.13 & 89.4 \\
\hline 62.1 & 20 & 5 & 20.0 & Nannofossil chalk ooze & 11.2 & 0.00 & 93.0 \\
\hline 62.1 & 20 & 6 & 20.0 & Nannofossil chalk ooze & 11.2 & 0.01 & 92.9 \\
\hline 62.1 & 21 & 1 & 20.0 & Nannofossil chalk ooze \& chalk & 10.7 & 0.00 & 88.8 \\
\hline 62.1 & 21 & 2 & 20.0 & Nannofossil chalk ooze \& chalk & 11.4 & 0.08 & 94.3 \\
\hline 62.1 & 21 & 3 & 21.0 & Nannofossil chalk ooze \& chalk & 10.7 & 0.00 & 89.4 \\
\hline
\end{tabular}


TABLE 3 - Continued

\begin{tabular}{|c|c|c|c|c|c|c|c|}
\hline Hole & Core & Section & $\begin{array}{c}\text { Top } \\
\text { Interval }\end{array}$ & Lithology & $\begin{array}{c}\text { Total } \\
\text { Carbon } \\
\text { (\% wt.) }\end{array}$ & $\begin{array}{l}\text { Organic } \\
\text { Carbon } \\
\text { (\% wt.) }\end{array}$ & $\begin{array}{c}\text { Calcium } \\
\text { Carbonate } \\
\text { (\% wt.) }\end{array}$ \\
\hline 62.1 & 21 & 4 & 25.0 & Nannofossil chalk ooze \& chalk & 10.0 & 0.03 & 83.3 \\
\hline 62.1 & 21 & 5 & 20.0 & Nannofossil chalk ooze \& chalk & 11.3 & 0.05 & 93.4 \\
\hline 62.1 & 21 & 6 & 23.0 & Nannofossil chalk ooze \& chalk & 8.9 & 0.00 & 74.5 \\
\hline 62.1 & 22 & 1 & 20.0 & Nannofossil chalk ooze \& chalk & 11.1 & 0.00 & 92.2 \\
\hline 62.1 & 22 & 2 & 20.0 & Nannofossil chalk ooze \& chalk & 11.1 & 0.00 & 92.6 \\
\hline 62.1 & 22 & 3 & 20.0 & Nannofossil chalk ooze \& chalk & 10.8 & 0.05 & 89.8 \\
\hline 62.1 & 22 & 4 & 20.0 & Nannofossil chalk ooze \& chalk & 10.9 & 0.08 & 90.5 \\
\hline 62.1 & 22 & 5 & 20.0 & Nannofossil chalk ooze \& chalk & 11.1 & 0.00 & 92.1 \\
\hline 62.1 & 22 & 6 & 20.0 & Nannofossil chalk ooze \& chalk & 11.0 & 0.01 & 91.4 \\
\hline 62.1 & 23 & 1 & 20.0 & Nannofossil chalk ooze \& chalk & 10.6 & 0.01 & 87.9 \\
\hline 62.1 & 23 & 2 & 20.0 & Nannofossil chalk ooze \& chalk & 9.1 & 0.03 & 75.2 \\
\hline 62.1 & 23 & 3 & 20.0 & Nannofossil chalk ooze \& chalk & 7.2 & 0.01 & 60.3 \\
\hline 62.1 & 23 & 4 & 20.0 & Nannofossil chalk ooze \& chalk & 10.7 & 0.01 & 89.2 \\
\hline 62.1 & 23 & 5 & 20.0 & Nannofossil chalk ooze \& chalk & 8.4 & 0.00 & 69.6 \\
\hline 62.1 & 23 & 6 & 20.0 & Nannofossil chalk ooze \& chalk & 11.0 & 0.07 & 91.1 \\
\hline 62.1 & 24 & 1 & 20.0 & Nannofossil chalk \& chalk ooze & 11.7 & 0.00 & 97.5 \\
\hline 62.1 & 24 & 2 & 47.0 & Nannofossil chalk \& chalk ooze & 11.3 & 0.00 & 94.0 \\
\hline 62.1 & 24 & 3 & 20.0 & Nannofossil chalk \& chalk ooze & 10.8 & 0.01 & 90.0 \\
\hline 62.1 & 24 & 4 & 20.0 & Nannofossil chalk \& chalk ooze & 10.9 & 0.00 & 90.5 \\
\hline 62.1 & 24 & 5 & 20.0 & Nannofossil chalk \& chalk ooze & 8.3 & 0.00 & 69.1 \\
\hline 62.1 & 24 & 6 & 20.0 & Nannofossil chalk \& chalk ooze & 10.3 & 0.00 & 86.0 \\
\hline 62.1 & 25 & 1 & 20.0 & Nannofossil chalk \& chalk ooze & 10.9 & 0.04 & 90.5 \\
\hline 62.1 & 25 & 2 & 20.0 & Nannofossil chalk \& chalk ooze & 10.5 & 0.05 & 87.1 \\
\hline 62.1 & 25 & 3 & 21.0 & Nannofossil chalk \& chalk ooze & 10.7 & 0.01 & 88.7 \\
\hline 62.1 & 25 & 4 & 20.0 & Nannofossil chalk \& chalk ooze & 10.3 & 0.02 & 85.3 \\
\hline 62.1 & 25 & 5 & 20.0 & Nannofossil chalk \& chalk ooze & 10.5 & 0.00 & 87.3 \\
\hline 62.1 & 26 & 1 & 20.0 & Nannofossil chalk \& chalk ooze & 9.2 & 0.03 & 76.4 \\
\hline 62.1 & 26 & 3 & 22.0 & Nannofossil chalk \& chalk ooze & 10.2 & 0.00 & 84.8 \\
\hline 62.1 & 26 & 4 & 20.0 & Nannofossil chalk \& chalk ooze & 10.2 & 0.04 & 84.3 \\
\hline 62.1 & 26 & 5 & 20.0 & Nannofossil chalk \& chalk ooze & 11.2 & 0.06 & 93.1 \\
\hline 62.1 & 26 & 6 & 20.0 & Nannofossil chalk \& chalk ooze & 10.2 & 0.00 & 85.3 \\
\hline 62.1 & 27 & 1 & 82.0 & Nannofossil chalk \& chalk ooze & 10.7 & 0.00 & 89.5 \\
\hline 62.1 & 27 & 2 & 20.0 & Nannofossil chalk \& chalk ooze & 10.3 & 0.00 & 86.0 \\
\hline 62.1 & 27 & 3 & 29.0 & Nannofossil chalk \& chalk ooze & 8.9 & 0.00 & 74.3 \\
\hline 62.1 & 27 & 4 & 20.0 & Nannofossil chalk \& chalk ooze & 10.6 & 0.00 & 88.0 \\
\hline 62.1 & 27 & 5 & 20.0 & Nannofossil chalk \& chalk ooze & 10.8 & 0.00 & 89.6 \\
\hline 62.1 & 28 & 1 & 18.0 & Nannofossil chalk \& chalk ooze & 10.4 & 0.07 & 85.9 \\
\hline 62.1 & 28 & 2 & 20.0 & Nannofossil chalk \& chalk ooze & 10.6 & 0.21 & 86.8 \\
\hline 62.1 & 28 & 3 & 47.0 & Nannofossil chalk \& chalk ooze & 10.8 & 0.95 & 81.7 \\
\hline
\end{tabular}


TABLE 3 - Continued

\begin{tabular}{|c|c|c|c|c|c|c|c|}
\hline Hole & Core & Section & $\begin{array}{c}\text { Top } \\
\text { Interval }\end{array}$ & Lithology & $\begin{array}{l}\text { Total } \\
\text { Carbon } \\
\text { (\% wt.) }\end{array}$ & $\begin{array}{l}\text { Organic } \\
\text { Carbon } \\
\text { (\% wt.) }\end{array}$ & $\begin{array}{c}\text { Calcium } \\
\text { Carbonate } \\
\text { (\% wt.) }\end{array}$ \\
\hline 62.1 & 28 & 4 & 21.0 & Nannofossil chalk \& chalk ooze & 10.2 & 1.30 & 74.3 \\
\hline 62.1 & 28 & 5 & 25.0 & Nannofossil chalk \& chalk ooze & 10.5 & 0.87 & 80.4 \\
\hline 62.1 & 28 & 6 & 21.0 & Nannofossil chalk \& chalk ooze & 6.6 & 0.33 & 51.9 \\
\hline 62.1 & 29 & 1 & 20.0 & Nannofossil chalk \& chalk ooze & 11.1 & 0.09 & 92.0 \\
\hline 62.1 & 29 & 2 & 20.0 & Nannofossil chalk \& chalk ooze & 10.4 & 0.01 & 86.4 \\
\hline 62.1 & 29 & 3 & 20.0 & Nannofossil chalk \& chalk ooze & 10.2 & 0.09 & 84.5 \\
\hline 62.1 & 29 & 4 & 20.0 & Nannofossil chalk \& chalk ooze & 10.2 & 0.05 & 84.4 \\
\hline 62.1 & 29 & 5 & 20.0 & Nannofossil chalk \& chalk ooze & 10.4 & 0.00 & 86.4 \\
\hline 62.1 & 29 & 6 & 20.0 & Nannofossil chalk \& chalk ooze & 10.2 & 0.00 & 85.1 \\
\hline 62.1 & 30 & 1 & 19.0 & Nannofossil chalk \& chalk ooze & 10.5 & 0.04 & 87.5 \\
\hline 62.1 & 30 & 2 & 20.0 & Nannofossil chalk \& chalk ooze & 10.5 & 0.00 & 87.5 \\
\hline 62.1 & 30 & 3 & 20.0 & Nannofossil chalk \& chalk ooze & 10.5 & 0.00 & 87.6 \\
\hline 62.1 & 30 & 4 & 20.0 & Nannofossil chalk \& chalk ooze & 10.9 & 0.00 & 90.8 \\
\hline 62.1 & 30 & 5 & 20.0 & Nannofossil chalk \& chalk ooze & 10.7 & 0.00 & 89.1 \\
\hline 62.1 & 30 & 6 & 20.0 & Nannofossil marl \& marl ooze & 4.9 & 0.00 & 40.7 \\
\hline 62.1 & 31 & 1 & 20.0 & Nannofossil chalk \& chalk ooze & 10.5 & 0.00 & 87.6 \\
\hline 62.1 & 31 & 2 & 20.0 & Nannofossil chalk \& chalk ooze & 10.3 & 0.00 & 85.8 \\
\hline 62.1 & 31 & 3 & 20.0 & Nannofossil chalk \& chalk ooze & 10.5 & 0.00 & 87.1 \\
\hline 62.1 & 31 & 4 & 20.0 & Nannofossil chalk \& chalk ooze & 10.3 & 0.00 & 86.0 \\
\hline 62.1 & 31 & 5 & 20.0 & Nannofossil chalk \& chalk ooze & 10.6 & 0.00 & 88.1 \\
\hline 62.1 & 31 & 6 & 20.0 & Nannofossil chalk \& chalk ooze & 10.7 & 0.00 & 89.5 \\
\hline 62.1 & 32 & 1 & 20.0 & Nannofossil chalk & 10.7 & 0.00 & 89.3 \\
\hline 62.1 & 32 & 2 & 20.0 & Nannofossil chalk & 10.9 & 0.00 & 90.6 \\
\hline 62.1 & 32 & 3 & 20.0 & Nannofossil chalk & 11.2 & 0.00 & 93.0 \\
\hline 62.1 & 32 & 4 & 20.0 & Nannofossil chalk & 8.9 & 0.00 & 74.3 \\
\hline 62.1 & 32 & 5 & 20.0 & Nannofossil chalk & 10.7 & 0.00 & 89.3 \\
\hline 62.1 & 32 & 6 & 20.0 & Nannofossil chalk & 10.4 & 0.01 & 86.6 \\
\hline 62.1 & 33 & 2 & 20.0 & Nannofossil chalk & 10.0 & 0.00 & 83.6 \\
\hline 62.1 & 33 & 3 & 20.0 & Nannofossil chalk & 9.7 & 0.00 & 80.8 \\
\hline 62.1 & 34 & 1 & 41.0 & Nannofossil chalk & 9.8 & 0.00 & 81.3 \\
\hline 62.1 & 34 & 2 & 22.0 & Nannofossil chalk & 10.2 & 0.02 & 85.1 \\
\hline 62.1 & 34 & 3 & 20.0 & Nannofossil chalk & 9.3 & 0.00 & 77.6 \\
\hline 62.1 & 34 & 4 & 20.0 & Nannofossil chalk & 9.9 & 0.02 & 82.7 \\
\hline 62.1 & 34 & 5 & 20.0 & Nannofossil chalk & 10.3 & 0.00 & 85.6 \\
\hline 62.1 & 34 & 6 & 20.0 & Nannofossil chalk & 10.5 & 0.07 & 86.9 \\
\hline 62.1 & 35 & 1 & 20.0 & Nannofossil chalk & 9.4 & 0.11 & 77.5 \\
\hline 62.1 & 35 & 2 & 20.0 & Nannofossil chalk & 10.0 & 0.00 & 83.3 \\
\hline 62.1 & 35 & 3 & 20.0 & Nannofossil chalk & 10.2 & 0.00 & 84.6 \\
\hline 62.1 & 35 & 4 & 20.0 & Nannofossil chalk & 10.0 & 0.00 & 83.6 \\
\hline
\end{tabular}


TABLE 3 - Continued

\begin{tabular}{|c|c|c|c|c|c|c|c|}
\hline Hole & Core & Section & $\begin{array}{c}\text { Top } \\
\text { Interval }\end{array}$ & Lithology & $\begin{array}{c}\text { Total } \\
\text { Carbon } \\
\text { (\% wt.) }\end{array}$ & $\begin{array}{l}\text { Organic } \\
\text { Carbon } \\
\text { (\% wt.) }\end{array}$ & $\begin{array}{c}\text { Calcium } \\
\text { Carbonate } \\
\text { (\% wt.) }\end{array}$ \\
\hline 62.1 & 35 & 5 & 20.0 & Nannofossil chalk & 9.6 & 0.00 & 80.0 \\
\hline 62.1 & 35 & 6 & 20.0 & Nannofossil chalk & 10.2 & 0.00 & 84.6 \\
\hline 62.1 & 36 & 2 & 20.0 & Nannofossil chalk & 10.2 & 0.00 & 84.8 \\
\hline 62.1 & 36 & 3 & 20.0 & Nannofossil chalk & 10.0 & 0.00 & 83.3 \\
\hline 62.1 & 36 & 4 & 20.0 & Nannofossil chalk & 10.6 & 0.00 & 88.3 \\
\hline 62.1 & 36 & 5 & 20.0 & Nannofossil chalk & 10.3 & 0.00 & 85.5 \\
\hline 62.1 & 37 & 2 & 20.0 & Nannofossil chalk & 10.0 & 0.00 & 83.6 \\
\hline 63.0 & 1 & 1 & 21.0 & Pelagic clay & 0.7 & 0.25 & 3.6 \\
\hline 63.0 & 1 & 2 & 21.0 & Pelagic clay & 1.1 & 0.17 & 8.0 \\
\hline 63.0 & 1 & 3 & 21.0 & Calcareous pelagic clay & 1.4 & 0.14 & 10.6 \\
\hline 63.0 & 1 & 4 & 21.0 & Calcareous pelagic clay & 1.7 & 0.22 & 12.0 \\
\hline 63.0 & 1 & 5 & 21.0 & Pelagic clay & 1.1 & 0.15 & 8.3 \\
\hline 63.0 & 1 & 6 & 30.0 & Calcareous pelagic clay & 1.6 & 0.42 & 10.1 \\
\hline 63.0 & 2 & 2 & 21.0 & Nannofossil chalk ooze & 8.0 & 0.00 & 67.0 \\
\hline 63.0 & 2 & 3 & 21.0 & Nannofossil chalk ooze & 9.7 & 0.00 & 81.0 \\
\hline 63.0 & 2 & 4 & 21.0 & Nannofossil chalk ooze & 9.6 & 0.00 & 79.6 \\
\hline 63.0 & 2 & 5 & 21.0 & Nannofossil chalk ooze & 9.7 & 0.00 & 81.0 \\
\hline 63.0 & 2 & 6 & 21.0 & Nannofossil chalk ooze & 7.5 & 0.20 & 61.0 \\
\hline 63.0 & 3 & 1 & 61.0 & Nannofossil chalk ooze & 8.6 & 0.00 & 72.0 \\
\hline 63.0 & 3 & 2 & 21.0 & Nannofossil chalk ooze & 7.7 & 0.00 & 64.0 \\
\hline 63.0 & 3 & 3 & 21.0 & Nannofossil chalk ooze & 9.5 & 0.00 & 79.1 \\
\hline 63.0 & 3 & 4 & 21.0 & Nannofossil marl ooze & 6.8 & 0.00 & 56.6 \\
\hline 63.0 & 4 & 1 & 21.0 & Nannofossil chalk ooze & 9.2 & 0.00 & 76.4 \\
\hline 63.0 & 4 & 2 & 21.0 & Nannofossil chalk ooze & 9.3 & 0.00 & 77.8 \\
\hline 63.0 & 5 & 1 & 36.0 & Nannofossil chalk & 9.2 & 0.00 & 76.6 \\
\hline 63.0 & 5 & 2 & 21.0 & Nannofossil chalk & 9.7 & 0.00 & 80.6 \\
\hline 63.0 & 6 & 1 & 26.0 & Nannofossil chalk & 10.8 & 0.00 & 88.6 \\
\hline 63.0 & 6 & 2 & 21.0 & Nannofossil chalk & 10.9 & 0.00 & 90.6 \\
\hline 63.0 & 6 & 3 & 26.0 & Nannofossil chalk & 10.8 & 0.00 & 90.0 \\
\hline 63.0 & 6 & 4 & 23.0 & Nannofossil chalk & 11.3 & 0.00 & 94.1 \\
\hline 63.0 & 6 & 5 & 23.0 & Nannofossil chalk & 10.8 & 0.00 & 90.0 \\
\hline 63.0 & 6 & 6 & 20.0 & Nannofossil chalk & 11.7 & 0.00 & 97.8 \\
\hline 63.0 & 7 & 1 & 25.0 & Nannofossil chalk & 10.5 & 0.00 & 87.2 \\
\hline 63.0 & 7 & 2 & 20.0 & Nannofossil chalk & 10.9 & 0.21 & 89.2 \\
\hline 63.0 & 7 & 3 & 20.0 & Nannofossil chalk & 10.4 & 0.00 & 86.3 \\
\hline 63.0 & 7 & 4 & 25.0 & Nannofossil chalk & 10.5 & 0.00 & 87.5 \\
\hline 63.0 & 7 & 5 & 20.0 & Nannofossil chalk & 10.6 & 0.00 & 88.0 \\
\hline 63.0 & 7 & 6 & 20.0 & Nannofossil chalk & 11.3 & 0.00 & 94.0 \\
\hline 63.0 & 8 & 1 & 90.0 & Nannofossil chalk & 10.9 & 0.00 & 91.0 \\
\hline
\end{tabular}


TABLE 3 - Continued

\begin{tabular}{|c|c|c|c|c|c|c|c|}
\hline Hole & Core & Section & $\begin{array}{c}\text { Top } \\
\text { Interval }\end{array}$ & Lithology & $\begin{array}{c}\text { Total } \\
\text { Carbon } \\
\text { (\% wt.) }\end{array}$ & $\begin{array}{l}\text { Organic } \\
\text { Carbon } \\
\text { (\% wt.) }\end{array}$ & $\begin{array}{c}\text { Calcium } \\
\text { Carbonate } \\
\text { (\% wt.) }\end{array}$ \\
\hline 63.0 & 8 & 2 & 28.0 & Nannofossil chalk & 10.7 & 0.00 & 89.1 \\
\hline 63.0 & 8 & 3 & 21.0 & Nannofossil chalk & 10.2 & 0.00 & 85.0 \\
\hline 63.0 & 9 & 1 & 21.0 & Nannofossil chalk & 11.0 & 0.00 & 91.3 \\
\hline 63.0 & 9 & 2 & 20.0 & Nannofossil chalk & 11.0 & 0.00 & 91.6 \\
\hline 63.0 & 9 & 3 & 20.0 & Nannofossil chalk & 11.1 & 0.12 & 91.8 \\
\hline 63.0 & 9 & 4 & 58.0 & Nannofossil chalk & 10.7 & 0.00 & 89.1 \\
\hline 63.1 & 1 & 1 & 60.0 & Calcareous pelagic clay & 2.8 & 0.04 & 22.7 \\
\hline 63.1 & 1 & 2 & 20.0 & Calcareous pelagic clay & 1.6 & 0.14 & 12.2 \\
\hline 63.1 & 1 & 3 & 20.0 & Calcareous pelagic clay & 2.7 & 0.08 & 21.5 \\
\hline 63.1 & 1 & 4 & 20.0 & Calcareous pelagic clay & 1.4 & 0.10 & 11.0 \\
\hline 63.1 & 3 & 1 & 90.0 & Nannofossil-foraminiferal marl ooze & 3.9 & 0.19 & 30.5 \\
\hline 63.1 & 3 & 2 & 20.0 & Calcareous pelagic clay & 3.8 & 0.21 & 29.7 \\
\hline 63.1 & 5 & 1 & 90.0 & Nannofossil chalk ooze & 7.5 & 0.05 & 62.4 \\
\hline 63.1 & 5 & 2 & 20.0 & Nannofossil chalk ooze & 7.6 & 0.03 & 63.0 \\
\hline 63.1 & 5 & 3 & 20.0 & Nannofossil chalk ooze & 8.6 & 0.05 & 71.2 \\
\hline 63.1 & 5 & 4 & 20.0 & Nannofossil marl ooze & 5.7 & 0.22 & 45.3 \\
\hline 63.1 & 6 & 1 & 69.0 & Nannofossil marl ooze & 6.4 & 0.05 & 53.2 \\
\hline 63.1 & 6 & 2 & 20.0 & Nannofossil marl ooze & 4.4 & 0.01 & 36.4 \\
\hline 63.1 & 6 & 3 & 22.0 & Nannofossil marl ooze & 5.6 & 0.09 & 45.5 \\
\hline 63.1 & 6 & 4 & 20.0 & Nannofossil marl ooze & 6.5 & 0.15 & 53.3 \\
\hline 63.1 & 6 & 5 & 20.0 & Nannofossil marl ooze & 5.5 & 0.11 & 44.5 \\
\hline 63.1 & 6 & 6 & 20.0 & Nannofossil marl ooze & 6.6 & 0.02 & 54.8 \\
\hline 63.1 & 7 & 2 & 20.0 & Chalk ooze & 8.5 & 0.00 & 71.0 \\
\hline 63.1 & 7 & 3 & 20.0 & Marl ooze & 6.8 & 0.00 & 56.5 \\
\hline 63.1 & 7 & 4 & 20.0 & Marl ooze & 5.5 & 0.11 & 44.9 \\
\hline 63.1 & 8 & 3 & 25.0 & Nannofossil chalk ooze & 7.4 & 0.00 & 61.6 \\
\hline 63.1 & 8 & 4 & 80.0 & Nannofossil chalk ooze & 7.5 & 0.00 & 62.8 \\
\hline 63.1 & 8 & 5 & 51.0 & Nannofossil marl ooze & 7.1 & 0.00 & 59.3 \\
\hline 63.1 & 8 & 6 & 10.0 & Nannofossil marl ooze & 6.5 & 0.05 & 53.5 \\
\hline 63.1 & 9 & 1 & 130.0 & Nannofossil chalk & 8.8 & 0.00 & 73.6 \\
\hline 63.1 & 9 & 2 & 46.0 & Nannofossil chalk & 8.2 & 0.00 & 68.6 \\
\hline 63.1 & 9 & 3 & 19.0 & Nannofossil chalk & 9.3 & 0.00 & 77.6 \\
\hline 63.1 & 9 & 4 & 38.0 & Nannofossil chalk & 8.6 & 0.00 & 71.3 \\
\hline 63.1 & 9 & 5 & 55.0 & Nannofossil chalk & 7.7 & 0.08 & 63.5 \\
\hline 63.1 & 9 & 6 & 26.0 & Nannofossil chalk & 9.8 & 0.11 & 81.1 \\
\hline 63.1 & 10 & 1 & 115.0 & Nannofossil chalk & 8.5 & 0.03 & 70.4 \\
\hline 63.1 & 10 & 2 & 38.0 & Nannofossil marl & 6.5 & 0.07 & 53.3 \\
\hline 63.1 & 10 & 3 & 29.0 & Nannofossil chalk & 9.5 & 0.93 & 71.7 \\
\hline 63.1 & 10 & 4 & 24.0 & Nannofossil chalk & 7.9 & 0.09 & 65.2 \\
\hline
\end{tabular}


TABLE 3 - Continued

\begin{tabular}{|c|c|c|c|c|c|c|c|}
\hline Hole & Core & Section & $\begin{array}{c}\text { Top } \\
\text { Interval }\end{array}$ & Lithology & $\begin{array}{l}\text { Total } \\
\text { Carbon } \\
\text { (\% wt.) }\end{array}$ & $\begin{array}{l}\text { Organic } \\
\text { Carbon } \\
\text { (\% wt.) } \\
\end{array}$ & $\begin{array}{c}\text { Calcium } \\
\text { Carbonate } \\
\text { (\% wt.) }\end{array}$ \\
\hline 63.1 & 10 & 5 & 25.0 & Nannofossil chalk & 9.5 & 0.00 & 79.6 \\
\hline 63.1 & 11 & 1 & 20.0 & Nannofossil chalk & 9.9 & 0.00 & 82.1 \\
\hline 63.1 & 11 & 2 & 45.0 & Nannofossil chalk & 8.0 & 0.12 & 65.6 \\
\hline 63.1 & 11 & 3 & 36.0 & Nannofossil chalk & 8.5 & 0.00 & 70.6 \\
\hline 63.1 & 11 & 4 & 26.0 & Nannofossil chalk & 9.4 & 0.00 & 78.0 \\
\hline 63.1 & 11 & 5 & 20.0 & Nannofossil chalk & 10.0 & 0.04 & 82.6 \\
\hline 63.1 & 11 & 6 & 20.0 & Nannofossil chalk & 8.5 & 0.05 & 70.6 \\
\hline 63.1 & 12 & 2 & 20.0 & Nannofossil chalk & 9.9 & 0.07 & 82.1 \\
\hline 63.1 & 13 & 1 & 17.0 & Nannofossil chalk & 9.3 & 0.08 & 76.5 \\
\hline 63.1 & 13 & 2 & 23.0 & Nannofossil chalk & 8.9 & 0.05 & 73.9 \\
\hline 63.1 & 13 & 3 & 56.0 & Nannofossil chalk & 9.4 & 0.00 & 78.0 \\
\hline 63.1 & 13 & 4 & 24.0 & Nannofossil chalk & 7.3 & 0.00 & 60.8 \\
\hline 63.1 & 13 & 5 & 25.0 & Nannofossil chalk & 8.7 & 0.00 & 72.3 \\
\hline 63.1 & 13 & 6 & 23.0 & Nannofossil marl & 5.7 & 0.15 & 46.3 \\
\hline 63.1 & 14 & 1 & 16.0 & Nannofossil chalk & 8.3 & 0.12 & 68.0 \\
\hline 63.1 & 14 & 2 & 18.0 & Nannofossil chalk & 9.8 & 0.14 & 80.3 \\
\hline 63.1 & 14 & 3 & 29.0 & Nannofossil chalk & 9.0 & 0.18 & 73.8 \\
\hline 63.1 & 14 & 4 & 20.0 & Nannofossil marl & 7.1 & 0.15 & 58.1 \\
\hline 63.1 & 14 & 5 & 12.0 & Nannofossil chalk & 10.1 & 0.13 & 83.2 \\
\hline 63.2 & 1 & 3 & 10.0 & Calcareous pelagic clay & 3.6 & 0.33 & 26.9 \\
\hline 63.2 & 1 & 4 & 20.0 & Calcareous pelagic clay & 2.4 & 0.30 & 17.8 \\
\hline 63.2 & 2 & 1 & 20.0 & Calcareous pelagic clay & 1.0 & 0.33 & 5.9 \\
\hline 63.2 & 2 & 2 & 20.0 & Calcareous pelagic clay & 3.8 & 0.45 & 27.8 \\
\hline 63.2 & 2 & 3 & 20.0 & Calcareous pelagic clay & 2.5 & 0.40 & 17.3 \\
\hline 63.2 & 2 & 4 & 20.0 & Calcareous pelagic clay & 2.9 & 0.39 & 21.1 \\
\hline 63.2 & 2 & 6 & 20.0 & Calcareous pelagic clay & 2.5 & 0.45 & 17.0 \\
\hline 63.2 & 3 & 1 & 50.0 & Calcareous pelagic clay & 2.3 & 0.24 & 17.0 \\
\hline 63.2 & 3 & 2 & 20.0 & Calcareous pelagic clay & 1.8 & 0.16 & 14.1 \\
\hline 63.2 & 3 & 3 & 20.0 & Nannofossil marl ooze & 6.4 & 0.13 & 52.2 \\
\hline 63.2 & 3 & 4 & 20.0 & Nannofossil marl ooze & 6.6 & 0.05 & 54.2 \\
\hline 64.0 & 1 & 1 & 2.0 & $\begin{array}{l}\text { Foraminifera, nannofossil } \\
\quad \text { chalk ooze }\end{array}$ & 9.9 & 0.00 & 82.87 \\
\hline 64.0 & 1 & 1 & 20.0 & $\begin{array}{l}\text { Foraminifera, nannofossil } \\
\text { chalk ooze }\end{array}$ & 9.8 & 0.00 & 81.3 \\
\hline 64.0 & 1 & 1 & 47.0 & $\begin{array}{l}\text { Foraminifera, nannofossil } \\
\text { chalk ooze }\end{array}$ & 9.6 & 0.01 & 79.7 \\
\hline 64.0 & 1 & 1 & 67.0 & $\begin{array}{l}\text { Foraminifera, nannofossil } \\
\text { chalk ooze }\end{array}$ & 9.7 & 0.00 & 80.5 \\
\hline 64.0 & 1 & 1 & 135.0 & $\begin{array}{l}\text { Foraminifera, nannofossil } \\
\text { chalk ooze }\end{array}$ & 9.8 & 0.00 & 82.0 J \\
\hline
\end{tabular}


TABLE 3 - Continued

\begin{tabular}{|c|c|c|c|c|c|c|c|c|}
\hline Hole & Core & Section & $\begin{array}{l}\text { Top } \\
\text { Interval }\end{array}$ & Lithology & $\begin{array}{l}\text { Total } \\
\text { Carbon } \\
\text { (\% wt.) }\end{array}$ & $\begin{array}{l}\text { Organic } \\
\text { Carbon } \\
\text { (\% wt.) }\end{array}$ & $\begin{array}{c}\text { Calcium } \\
\text { Carbonate } \\
\text { (\% wt.) }\end{array}$ & \\
\hline 64.0 & 1 & 2 & 50.0 & $\begin{array}{l}\text { Foraminifera, nannofossil } \\
\text { chalk ooze }\end{array}$ & 9.7 & 0.00 & $81.1)$ & \\
\hline 64.0 & 1 & 2 & 95.0 & $\begin{array}{l}\text { Foraminifera, nannofossil } \\
\text { chalk ooze }\end{array}$ & 9.6 & 0.00 & 79.8 & \\
\hline 64.0 & 1 & 2 & 110.0 & $\begin{array}{l}\text { Foraminifera, nannofossil } \\
\text { chalk ooze }\end{array}$ & 9.6 & 0.00 & 80.3 & $\infty$ \\
\hline 64.0 & 1 & 2 & 121.0 & $\begin{array}{l}\text { Foraminifera, nannofossil } \\
\text { chalk ooze }\end{array}$ & 9.4 & 0.00 & 78.3 & \\
\hline 64.0 & 1 & 2 & 131.0 & $\begin{array}{l}\text { Foraminifera, nannofossil } \\
\text { chalk ooze }\end{array}$ & 9.0 & 0.03 & 74.4 J & \\
\hline 64.0 & 1 & 3 & 16.0 & $\begin{array}{l}\text { Foraminifera, nannofossil } \\
\text { chalk ooze }\end{array}$ & 9.3 & 0.00 & 77.8 & \\
\hline 64.0 & 1 & 3 & 40.0 & $\begin{array}{l}\text { Foraminifera, nannofossil } \\
\text { chalk ooze }\end{array}$ & 9.7 & 0.00 & 80.6 & $-\infty$ \\
\hline 64.0 & 1 & 3 & 131.0 & $\begin{array}{l}\text { Foraminifera, nannofossil } \\
\text { chalk ooze }\end{array}$ & 10.3 & 0.00 & 85.8 & \\
\hline 64.0 & 1 & 4 & 20.0 & $\begin{array}{l}\text { Foraminifera, nannofossil } \\
\text { chalk ooze }\end{array}$ & 9.3 & 0.00 & 77.8 & \\
\hline 64.0 & 1 & 5 & 20.0 & $\begin{array}{l}\text { Foraminifera, nannofossil } \\
\text { chalk ooze }\end{array}$ & 9.9 & 0.00 & 82.6 & \\
\hline 64.0 & 1 & 6 & 88.0 & $\begin{array}{l}\text { Foraminifera, nannofossil } \\
\text { chalk ooze }\end{array}$ & 9.9 & 0.00 & 82.1 & \\
\hline 64.0 & 2 & 1 & 51.0 & $\begin{array}{l}\text { Foraminifera, nannofossil } \\
\text { chalk ooze }\end{array}$ & 10.4 & 0.00 & 86.6 & \\
\hline 64.0 & 2 & 2 & 20.0 & $\begin{array}{l}\text { Foraminifera, nannofossil } \\
\text { chalk ooze }\end{array}$ & 10.6 & 0.00 & 88.5 & \\
\hline 64.0 & 2 & 3 & 20.0 & $\begin{array}{l}\text { Foraminifera, nannofossil } \\
\text { chalk ooze }\end{array}$ & 10.6 & 0.00 & 88.6 & \\
\hline 64.0 & 2 & 6 & 20.0 & $\begin{array}{l}\text { Foraminifera, nannofossil } \\
\text { chalk ooze }\end{array}$ & 10.9 & 0.00 & 91.0 & \\
\hline 64.0 & 3 & 1 & 20.0 & Nannofossil chalk ooze & 11.1 & 0.00 & 92.7 & \\
\hline 64.0 & 3 & 2 & 20.0 & Nannofossil chalk ooze & 11.5 & 0.00 & 95.5 & \\
\hline 64.0 & 3 & 3 & 41.0 & Nannofossil chalk ooze & 10.3 & 0.00 & 86.1 & \\
\hline 64.0 & 3 & 4 & 20.0 & Nannofossil chalk ooze & 11.2 & 0.00 & 93.1 & \\
\hline 64.0 & 3 & 5 & 30.0 & Nannofossil chalk ooze & 11.0 & 0.00 & 91.6 & \\
\hline 64.0 & 3 & 6 & 50.0 & Nannofossil chalk ooze & 10.5 & 0.00 & 87.6 & \\
\hline 64.0 & 4 & 1 & 80.0 & Nannofossil chalk ooze & 10.7 & 0.00 & 89.0 & \\
\hline 64.0 & 4 & 2 & 85.0 & Nannofossil chalk ooze & 10.6 & 0.00 & 88.3 & \\
\hline 64.0 & 4 & 3 & 20.0 & Nannofossil chalk ooze & 10.2 & 0.00 & $84.6\}$ & 9 \\
\hline 64.0 & 4 & 3 & 37.0 & Nannofossil chalk ooze & 10.7 & 0.00 & $89.1\}$ & 8 \\
\hline 64.0 & 4 & 4 & 52.0 & Nannofossil chalk ooze & 8.5 & 0.00 & 71.0 & \\
\hline 64.0 & 4 & 5 & 110.0 & Nannofossil chalk ooze & 10.4 & 0.00 & 87.0 & \\
\hline 64.0 & 4 & 6 & 20.0 & Nannofossil chalk ooze & 10.9 & 0.00 & 91.0 & \\
\hline
\end{tabular}


TABLE 3 - Continued

\begin{tabular}{|c|c|c|c|c|c|c|c|}
\hline Hole & Core & Section & $\begin{array}{l}\text { Top } \\
\text { Interval }\end{array}$ & Lithology & $\begin{array}{c}\text { Total } \\
\text { Carbon } \\
\text { (\% wt.) }\end{array}$ & $\begin{array}{l}\text { Organic } \\
\text { Carbon } \\
\text { (\% wt.) }\end{array}$ & $\begin{array}{c}\text { Calcium } \\
\text { Carbonate } \\
\text { (\% wt.) }\end{array}$ \\
\hline 64.0 & 5 & 1 & 84.0 & Nannofossil chalk ooze & 10.9 & 0.00 & 90.5 \\
\hline 64.0 & 5 & 2 & 40.0 & Nannofossil chalk ooze & 10.4 & 0.00 & 86.3 \\
\hline 64.0 & 5 & 4 & 17.0 & Nannofossil chalk ooze & 10.6 & 0.00 & 88.3 \\
\hline 64.0 & 5 & 5 & 20.0 & Nannofossil chalk ooze & 10.0 & 0.00 & 83.6 \\
\hline 64.0 & 6 & 1 & 20.0 & Nannofossil marl ooze & 5.5 & 0.03 & 45.6 \\
\hline 64.0 & 6 & 2 & 20.0 & Nannofossil chalk ooze & 9.8 & 0.13 & 80.9 \\
\hline 64.0 & 6 & 3 & 20.0 & Nannofossil chalk ooze & 10.9 & 0.00 & 90.8 \\
\hline 64.0 & 6 & 4 & 19.0 & Nannofossil chalk ooze & 10.6 & 0.00 & 88.6 \\
\hline 64.0 & 6 & 5 & 20.0 & Nannofossil chalk ooze & 9.1 & 0.08 & 75.3 \\
\hline 64.0 & 7 & 1 & 30.0 & Nannofossil chalk & 10.3 & 0.15 & 84.7 \\
\hline 64.0 & 7 & 2 & 30.0 & Nannofossil chalk & 10.4 & 0.04 & 86.0 \\
\hline 64.0 & 7 & 3 & 29.0 & Nannofossil chalk & 10.5 & 0.07 & 86.9 \\
\hline 64.0 & 7 & 4 & 49.0 & Nannofossil chalk & 10.6 & 0.00 & 88.6 \\
\hline 64.0 & 7 & 5 & 53.0 & Nannofossil chalk & 10.8 & 0.07 & 89.4 \\
\hline 64.0 & 7 & 6 & 20.0 & Nannofossil chalk & 11.0 & 0.12 & 91.0 \\
\hline 64.0 & 8 & 2 & 20.0 & Nannofossil chalk & 10.3 & 0.04 & 85.9 \\
\hline 64.0 & 8 & 3 & 20.0 & Nannofossil chalk & 10.3 & 0.00 & 86.1 \\
\hline 64.0 & 10 & 1 & 27.0 & $\begin{array}{l}\text { Nannofossil chalk and } \\
\text { limestone }\end{array}$ & 10.6 & 0.07 & 87.9 \\
\hline 64.0 & 10 & 2 & 20.0 & $\begin{array}{l}\text { Nannofossil chalk and } \\
\text { limestone }\end{array}$ & 10.2 & 0.02 & 84.5 \\
\hline 64.1 & 1 & 1 & 28.0 & Nannofossil chalk ooze & 10.9 & 0.04 & 90.7 \\
\hline 64.1 & 1 & 2 & 25.0 & Nannofossil chalk ooze & 9.6 & 0.07 & 79.7 \\
\hline 64.1 & 1 & 3 & 20.0 & Nannofossil chalk ooze & 8.4 & 0.08 & 69.3 \\
\hline 64.1 & 1 & 4 & 20.0 & Nannofossil chalk ooze & 10.8 & 0.02 & 90.1 \\
\hline 64.1 & 1 & 5 & 20.0 & Nannofossil chalk ooze & 10.9 & 0.00 & 90.8 \\
\hline 64.1 & 1 & 6 & 21.0 & Nannofossil chalk ooze & 10.4 & 0.07 & 86.4 \\
\hline 64.1 & 2 & 1 & 41.0 & $\begin{array}{l}\text { Nannofossil chalk and } \\
\text { chalk ooze }\end{array}$ & 10.1 & 0.02 & 83.6 \\
\hline 64.1 & 2 & 2 & 26.0 & $\begin{array}{l}\text { Nannofossil chalk and } \\
\text { chalk ooze }\end{array}$ & 10.2 & 0.00 & 85.0 \\
\hline 64.1 & 2 & 3 & 33.0 & $\begin{array}{l}\text { Nannofossil chalk and } \\
\text { chalk ooze }\end{array}$ & 10.0 & 0.13 & 82.0 \\
\hline 64.1 & 2 & 4 & 19.0 & $\begin{array}{l}\text { Nannofossil chalk and } \\
\text { chalk ooze }\end{array}$ & 10.6 & 0.00 & 88.6 \\
\hline 64.1 & 2 & 5 & 20.0 & $\begin{array}{l}\text { Nannofossil chalk and } \\
\text { chalk ooze }\end{array}$ & 10.7 & 0.02 & 88.6 \\
\hline 64.1 & 2 & 6 & 20.0 & $\begin{array}{l}\text { Nannofossil chalk and } \\
\text { chalk ooze }\end{array}$ & 11.0 & 0.00 & 91.5 \\
\hline 64.1 & 3 & 1 & 20.0 & $\begin{array}{l}\text { Nannofossil chalk and } \\
\text { chalk ooze }\end{array}$ & 10.7 & 0.00 & 89.3 \\
\hline
\end{tabular}


TABLE 3 - Continued

\begin{tabular}{|c|c|c|c|c|c|c|c|}
\hline Hole & Core & Section & $\begin{array}{c}\text { Top } \\
\text { Interval }\end{array}$ & Lithology & $\begin{array}{c}\text { Total } \\
\text { Carbon } \\
\text { (\% wt.) }\end{array}$ & $\begin{array}{l}\text { Organic } \\
\text { Carbon } \\
\text { (\% wt.) }\end{array}$ & $\begin{array}{c}\text { Calcium } \\
\text { Carbonate } \\
\text { (\% wt.) }\end{array}$ \\
\hline 64.1 & 3 & 2 & 22.0 & $\begin{array}{l}\text { Nannofossil chalk and } \\
\text { chalk ooze }\end{array}$ & 10.5 & 0.03 & 87.4 \\
\hline 64.1 & 3 & 3 & 20.0 & $\begin{array}{l}\text { Nannofossil chalk and } \\
\text { chalk ooze }\end{array}$ & 10.8 & 0.00 & 90.1 \\
\hline 64.1 & 3 & 4 & 32.0 & $\begin{array}{l}\text { Nannofossil chalk and } \\
\text { chalk ooze }\end{array}$ & 10.8 & 0.00 & 89.6 \\
\hline 64.1 & 3 & 5 & 25.0 & $\begin{array}{l}\text { Nannofossil chalk and } \\
\text { chalk ooze }\end{array}$ & 11.2 & 0.01 & 92.9 \\
\hline 64.1 & 3 & 6 & 20.0 & $\begin{array}{l}\text { Nannofossil chalk and } \\
\text { chalk ooze }\end{array}$ & 10.9 & 0.00 & 90.8 \\
\hline 64.1 & 4 & 1 & 18.0 & $\begin{array}{l}\text { Nannofossil chalk and } \\
\text { chalk ooze }\end{array}$ & 10.4 & 0.00 & 86.6 \\
\hline 64.1 & 4 & 2 & 20.0 & $\begin{array}{l}\text { Nannofossil chalk and } \\
\text { chalk ooze }\end{array}$ & 10.8 & 0.00 & 90.3 \\
\hline 64.1 & 4 & 4 & 15.0 & $\begin{array}{l}\text { Nannofossil chalk and } \\
\text { chalk ooze }\end{array}$ & 10.4 & 0.00 & 86.5 \\
\hline 64.1 & 4 & 5 & 20.0 & $\begin{array}{l}\text { Nannofossil chalk and } \\
\text { chalk ooze }\end{array}$ & 10.1 & 0.00 & 84.0 \\
\hline 64.1 & 4 & 6 & 20.0 & $\begin{array}{l}\text { Nannofossil chalk and } \\
\text { chalk ooze }\end{array}$ & 10.5 & 0.00 & 87.5 \\
\hline 64.1 & 5 & 1 & 32.0 & $\begin{array}{l}\text { Nannofossil chalk and } \\
\text { chalk ooze }\end{array}$ & 9.9 & 0.00 & 82.8 \\
\hline 64.1 & 5 & 2 & 104.0 & $\begin{array}{l}\text { Nannofossil chalk and } \\
\text { chalk ooze }\end{array}$ & 10.2 & 0.00 & 85.0 \\
\hline 65.0 & 2 & 1 & 62.0 & Radiolarian ooze & 0.3 & 0.36 & 0.0 \\
\hline 65.0 & 2 & 2 & 56.0 & Radiolarian ooze & 0.2 & 0.18 & 0.3 \\
\hline 65.0 & 2 & 3 & 24.0 & Radiolarian ooze & 0.5 & 0.26 & 1.6 \\
\hline 65.0 & 2 & 4 & 116.0 & Radiolarian ooze & 0.3 & 0.21 & 0.4 \\
\hline 65.0 & 2 & 5 & 50.0 & Radiolarian ooze & 0.3 & 0.19 & 0.6 \\
\hline 65.0 & 3 & 1 & 44.0 & Radiolarian ooze & 0.3 & 0.21 & 0.4 \\
\hline 65.0 & 3 & 2 & 40.0 & Radiolarian ooze & 0.3 & 0.18 & 0.7 \\
\hline 65.0 & 3 & 3 & 112.0 & Radiolarian ooze & 0.3 & 0.21 & 0.7 \\
\hline 65.0 & 3 & 4 & 55.0 & Radiolarian ooze & 0.3 & 0.21 & 0.5 \\
\hline 65.0 & 3 & 5 & 75.0 & Radiolarian ooze & 0.3 & 0.22 & 0.7 \\
\hline 65.0 & 5 & 2 & 41.0 & Radiolarian ooze & 0.2 & 0.16 & 0.4 \\
\hline 65.0 & 5 & 4 & 68.0 & Radiolarian ooze & 0.2 & 0.18 & 0.2 \\
\hline 65.0 & 5 & 5 & 40.0 & Radiolarian ooze & 0.4 & 0.25 & 1.6 \\
\hline 65.0 & 5 & 6 & 60.0 & Radiolarian ooze & 0.3 & 0.20 & 1.1 \\
\hline 65.0 & 6 & 2 & 134.0 & Radiolarian ooze & 0.3 & 0.19 & 1.0 \\
\hline 65.0 & 7 & 2 & 91.0 & Radiolarian ooze & 0.2 & 0.14 & 0.6 \\
\hline 65.0 & 7 & 3 & 43.0 & Radiolarian ooze & 0.2 & 0.13 & 1.0 \\
\hline 65.0 & 7 & 4 & 39.0 & Radiolarian ooze & 0.2 & 0.10 & 0.5 \\
\hline
\end{tabular}


TABLE 3 - Continued

\begin{tabular}{|c|c|c|c|c|c|c|c|}
\hline Hole & Core & Section & $\begin{array}{l}\text { Top } \\
\text { Interval }\end{array}$ & Lithology & $\begin{array}{l}\text { Total } \\
\text { Carbon } \\
\text { (\% wt.) }\end{array}$ & $\begin{array}{l}\text { Organic } \\
\text { Carbon } \\
\text { (\% wt.) }\end{array}$ & $\begin{array}{c}\text { Calcium } \\
\text { Carbonate } \\
\text { (\% wt.) }\end{array}$ \\
\hline 65.0 & 7 & 5 & 14.0 & Radiolarian ooze & 0.2 & 0.14 & 0.4 \\
\hline 65.0 & 8 & 1 & 94.0 & Radiolarian ooze & 0.2 & 0.11 & 0.8 \\
\hline 65.0 & 8 & 2 & 51.0 & Radiolarian ooze & 0.1 & 0.10 & 0.4 \\
\hline 65.0 & 8 & 3 & 78.0 & Radiolarian ooze & 0.4 & 0.08 & 3.0 \\
\hline 65.0 & 8 & 4 & 57.0 & Radiolarian ooze & 0.2 & 0.09 & 0.6 \\
\hline 65.0 & 8 & 5 & 107.0 & Radiolarian ooze & 0.2 & 0.12 & 0.6 \\
\hline 65.0 & 8 & 6 & 20.0 & Radiolarian ooze & 0.6 & 0.01 & 4.9 \\
\hline 65.0 & 9 & 1 & 32.0 & Radiolarian ooze & 0.2 & 0.11 & 0.3 \\
\hline 65.0 & 9 & 2 & 48.0 & Radiolarian ooze & 0.3 & 0.13 & 1.5 \\
\hline 65.0 & 9 & 3 & 110.0 & Radiolarian ooze & 0.2 & 0.13 & 0.6 \\
\hline 65.0 & 9 & 5 & 92.0 & Radiolarian ooze & 0.1 & 0.11 & 0.3 \\
\hline 65.0 & 10 & 1 & 90.0 & Radiolarian ooze & 0.2 & 0.09 & 1.2 \\
\hline 65.0 & 10 & 3 & 21.0 & Radiolarian ooze & 0.4 & 0.15 & 1.8 \\
\hline 65.0 & 10 & 4 & 115.0 & Radiolarian ooze & 0.2 & 0.15 & 0.0 \\
\hline 65.0 & 11 & 2 & 120.0 & Radiolarian ooze & 0.3 & 0.15 & 1.0 \\
\hline 65.0 & 11 & 3 & 40.0 & Radiolarian ooze & 0.1 & 0.10 & 0.3 \\
\hline 65.0 & 11 & 4 & 58.0 & Radiolarian ooze & 0.1 & 0.08 & 0.4 \\
\hline 65.0 & 11 & 5 & 117.0 & Radiolarian ooze & 0.2 & 0.07 & 0.7 \\
\hline 65.0 & 11 & 6 & 20.0 & Radiolarian ooze & 0.2 & 0.16 & 0.0 \\
\hline 65.0 & 12 & 1 & 73.0 & Radiolarian ooze & 0.2 & 0.04 & 1.5 \\
\hline 65.0 & 12 & 2 & 123.0 & Radiolarian ooze & 0.1 & 0.07 & 0.3 \\
\hline 65.0 & 12 & 3 & 9.0 & Radiolarian ooze & 0.1 & 0.07 & 0.3 \\
\hline 65.0 & 12 & 4 & 71.0 & Radiolarian ooze & 0.1 & 0.04 & 0.8 \\
\hline 65.0 & 12 & 4 & 118.0 & Radiolarian ooze & 0.1 & 0.10 & 0.1 \\
\hline 65.0 & 12 & 5 & 30.0 & Radiolarian ooze & 0.1 & 0.06 & 0.5 \\
\hline 65.0 & 12 & 6 & 135.0 & Radiolarian ooze & 0.1 & 0.05 & 0.4 \\
\hline 65.0 & 13 & 1 & 75.0 & Radiolarian ooze & 0.1 & 0.09 & 0.3 \\
\hline 65.0 & 13 & 2 & 65.0 & Radiolarian ooze & 0.1 & 0.17 & 0.0 \\
\hline 65.0 & 13 & 3 & 100.0 & Radiolarian ooze & 0.1 & 0.16 & 0.0 \\
\hline 65.0 & 13 & 4 & 20.0 & Radiolarian ooze & 0.1 & 0.06 & 0.6 \\
\hline 65.0 & 13 & 5 & 20.0 & Radiolarian ooze & 0.1 & 0.09 & 0.4 \\
\hline 65.0 & 13 & 6 & 20.0 & Radiolarian ooze & 0.2 & 0.07 & 0.7 \\
\hline 65.0 & 14 & 1 & 130.0 & Radiolarian ooze & 0.1 & 0.04 & 0.6 \\
\hline 65.0 & 14 & 2 & 125.0 & Radiolarian ooze & 0.1 & 0.09 & 0.3 \\
\hline 65.0 & 14 & 3 & 93.0 & Radiolarian ooze & 0.3 & 0.08 & 1.5 \\
\hline 65.0 & 14 & 4 & 79.0 & Radiolarian ooze & 0.1 & 0.08 & 0.5 \\
\hline 65.0 & 14 & 4 & 92.0 & Calcareous radiolarian ooze & 4.1 & 0.06 & 33.8 \\
\hline 65.0 & 14 & 4 & 112.0 & Calcareous radiolarian ooze & 0.3 & 0.06 & 2.0 \\
\hline 65.0 & 14 & 4 & 136.0 & Calcareous radiolarian ooze & 4.7 & 0.04 & 38.5 \\
\hline
\end{tabular}


TABLE 3 - Continued

\begin{tabular}{|c|c|c|c|c|c|c|c|}
\hline Hole & Core & Section & $\begin{array}{c}\text { Top } \\
\text { Interval }\end{array}$ & Lithology & $\begin{array}{l}\text { Total } \\
\text { Carbon } \\
\text { (\% wt.) }\end{array}$ & $\begin{array}{l}\text { Organic } \\
\text { Carbon } \\
\text { (\% wt.) }\end{array}$ & $\begin{array}{l}\text { Calcium } \\
\text { Carbonate } \\
\text { (\% wt.) }\end{array}$ \\
\hline 65.0 & 14 & 5 & 20.0 & Nannofossil radiolarian ooze & 4.1 & 0.05 & 33.6 \\
\hline 65.0 & 14 & 6 & 20.0 & Nannofossil radiolarian ooze & 4.5 & 0.06 & 37.2 \\
\hline 65.0 & 16 & 2 & 60.0 & Nannofossil radiolarian ooze & 1.8 & 0.07 & 14.1 \\
\hline 65.0 & 16 & 3 & 22.0 & Nannofossil radiolarian ooze & 1.8 & 0.04 & 14.5 \\
\hline 65.0 & 16 & 4 & 21.0 & Nannofossil radiolarian ooze & 0.4 & 0.05 & 2.7 \\
\hline 65.0 & 16 & 5 & 21.0 & Nannofossil radiolarian ooze & 0.5 & 0.07 & 4.0 \\
\hline 65.0 & 16 & 6 & 20.0 & Nannofossil radiolarian ooze & 0.2 & 0.00 & 1.3 \\
\hline 65.1 & 2 & 1 & 110.0 & Radiolarian marl ooze & 5.1 & 0.06 & 41.8 \\
\hline 65.1 & 4 & 1 & 100.0 & Radiolarian ooze & 0.2 & 0.07 & 0.9 \\
\hline 65.1 & 4 & 2 & 21.0 & Radiolarian ooze & 0.2 & 0.05 & 1.2 \\
\hline 65.1 & 4 & 3 & 20.0 & Radiolarian ooze & 0.1 & 0.02 & 0.8 \\
\hline 65.1 & 4 & 4 & 110.0 & Radiolarian ooze & 0.1 & 0.03 & 0.7 \\
\hline 65.1 & 4 & 5 & 30.0 & Radiolarian ooze & 0.1 & 0.01 & 0.8 \\
\hline 65.1 & 4 & 6 & 20.0 & Radiolarian ooze & 0.2 & 0.04 & 1.0 \\
\hline 65.1 & 5 & 1 & 100.0 & Radiolarian ooze with chert & 0.3 & 0.03 & 1.9 \\
\hline 65.1 & 5 & 2 & 20.0 & Radiolarian ooze with chert & 0.1 & 0.04 & 0.9 \\
\hline 65.1 & 5 & 3 & 130.0 & Radiolarian ooze with chert & 0.1 & 0.01 & 1.0 \\
\hline 65.1 & 5 & 4 & 20.0 & Radiolarian ooze with chert & 0.1 & 0.05 & 0.7 \\
\hline 65.1 & 5 & 5 & 132.0 & Radiolarian ooze with chert & 0.1 & 0.03 & 0.8 \\
\hline 66.0 & 2 & 1 & 20.0 & Radiolarian ooze & 0.1 & 0.15 & 0.0 \\
\hline 66.0 & 2 & 2 & 25.0 & Radiolarian ooze & 0.1 & 0.25 & 0.0 ไฯ \\
\hline 66.0 & 2 & 2 & 102.0 & Radiolarian ooze & 1.2 & 0.17 & $8.4\} \nabla$ \\
\hline 66.0 & 2 & 3 & 45.0 & Radiolarian ooze & 0.2 & 0.24 & 0.0 \\
\hline 66.0 & 3 & 1 & 51.0 & Radiolarian ooze & 0.1 & 0.22 & $0.0)_{\nabla}$ \\
\hline 66.0 & 3 & 1 & 63.0 & Radiolarian ooze & 0.3 & 0.23 & $0.7\}^{\circ}$ \\
\hline 66.0 & 3 & 2 & 35.0 & Radiolarian ooze & 0.1 & 0.00 & 1.2 \\
\hline 66.0 & 3 & 3 & 71.0 & Radiolarian ooze & 0.1 & 0.33 & 0.0 \\
\hline 66.0 & 3 & 6 & 87.0 & Radiolarian ooze & 0.0 & 0.11 & 0.0 \\
\hline 66.0 & 6 & 1 & 43.0 & Pelagic clay & 0.2 & 0.15 & 0.2 \\
\hline 66.0 & 6 & 2 & 20.0 & Pelagic clay & 0.2 & 0.16 & 0.1 \\
\hline 66.0 & 6 & 3 & 20.0 & Pelagic clay & 0.2 & 0.15 & 0.2 \\
\hline 66.0 & 6 & 4 & 20.0 & Pelagic clay & 0.2 & 0.17 & 0.0 \\
\hline 66.0 & 7 & 1 & 40.0 & Pelagic clay & 0.2 & 0.19 & 0.2 \\
\hline 66.0 & 7 & 2 & 20.0 & Pelagic clay & 0.2 & 0.16 & 0.1 \\
\hline 66.0 & 7 & 3 & 20.0 & Pelagic clay & 0.1 & 0.17 & 0.0 \\
\hline 66.0 & 7 & 4 & 20.0 & Pelagic clay & 0.2 & 0.19 & 0.0 \\
\hline 66.0 & 8 & 1 & 64.0 & Pelagic clay & 0.2 & 0.27 & 0.0 \\
\hline 66.0 & 8 & 2 & 33.0 & Pelagic clay & 0.2 & 0.18 & 0.0 \\
\hline
\end{tabular}


TABLE 3 - Continued

\begin{tabular}{|c|c|c|c|c|c|c|c|}
\hline Hole & Core & Section & $\begin{array}{c}\text { Top } \\
\text { Interval }\end{array}$ & Lithology & $\begin{array}{c}\text { Total } \\
\text { Carbon } \\
\text { (\% wt.) } \\
\end{array}$ & $\begin{array}{l}\text { Organic } \\
\text { Carbon } \\
(\% \text { wt.) } \\
\end{array}$ & $\begin{array}{c}\text { Calcium } \\
\text { Carbonate } \\
\text { (\% wt.) }\end{array}$ \\
\hline 66.0 & 8 & 3 & 30.0 & Pelagic clay & 0.2 & 0.18 & 0.0 \\
\hline 66.0 & 8 & 4 & 55.0 & Pelagic clay & 0.2 & 0.22 & 0.0 \\
\hline 66.0 & 8 & 5 & 52.0 & Pelagic clay & 0.2 & 0.26 & 0.0 \\
\hline 66.0 & 9 & 1 & 112.0 & Volcanic mud & 0.1 & 0.21 & 0.0 \\
\hline 66.0 & 9 & 3 & 140.0 & Volcanic mud & 0.2 & 0.21 & 0.2 \\
\hline 66.1 & 2 & 2 & 46.0 & Radiolarian ooze & 0.4 & 0.32 & 0.6 \\
\hline 66.1 & 2 & 3 & 28.0 & Radiolarian ooze & 0.3 & 0.33 & 0.0 \\
\hline 66.1 & 2 & 4 & 20.0 & Radiolarian ooze & 0.3 & 0.27 & 0.0 \\
\hline 66.1 & 2 & 5 & 20.0 & Radiolarian ooze & 0.3 & 0.24 & 0.5 \\
\hline 66.1 & 2 & 6 & 20.0 & Radiolarian ooze & 0.4 & 0.27 & 0.9 \\
\hline 66.1 & 3 & 2 & 20.0 & Radiolarian ooze & 0.3 & 0.25 & 0.2 \\
\hline 66.1 & 3 & 3 & 20.0 & Radiolarian ooze & 0.2 & 0.26 & 0.0 \\
\hline 66.1 & 3 & 4 & 20.0 & Radiolarian ooze & 0.2 & 0.31 & 0.0 \\
\hline 66.1 & 3 & 5 & 20.0 & Radiolarian ooze & 0.2 & 0.31 & 0.0 \\
\hline 66.1 & 3 & 6 & 18.0 & Radiolarian ooze & 0.3 & 0.33 & 0.0 \\
\hline 66.1 & 4 & 1 & 122.0 & Radiolarian ooze & 0.3 & 0.35 & 0.0 \\
\hline 66.1 & 4 & 2 & 55.0 & Radiolarian ooze & 0.2 & 0.30 & 0.0 \\
\hline 66.1 & 4 & 3 & 50.0 & Radiolarian ooze & 0.1 & 0.26 & 0.0 \\
\hline 66.1 & 4 & 4 & 13.0 & Radiolarian ooze & 0.1 & 0.22 & 0.0 \\
\hline 66.1 & 4 & 5 & 33.0 & Radiolarian ooze & 0.1 & 0.26 & 0.0 \\
\hline 66.1 & 4 & 6 & 46.0 & Radiolarian ooze & 0.1 & 0.26 & 0.0 \\
\hline 66.1 & 5 & 1 & 30.0 & Radiolarian ooze & 0.2 & 0.34 & 0.0 \\
\hline 66.1 & 5 & 2 & 75.0 & Radiolarian ooze & 0.1 & 0.26 & 0.0 \\
\hline 66.1 & 5 & 3 & 22.0 & Radiolarian ooze & 0.1 & 0.00 & 1.2 \\
\hline 66.1 & 5 & 4 & 24.0 & Radiolarian ooze & 0.0 & 0.28 & 0.0 \\
\hline 66.1 & 5 & 5 & 93.0 & Radiolarian ooze & 0.2 & 0.25 & 0.0 \\
\hline 66.1 & 5 & 6 & 75.0 & Radiolarian ooze & 0.1 & 0.24 & 0.0 \\
\hline 66.1 & 6 & 2 & 21.0 & Radiolarian ooze & 0.1 & 0.10 & 0.0 \\
\hline 66.1 & 6 & 3 & 36.0 & Radiolarian ooze & 0.1 & 0.24 & 0.0 \\
\hline 66.1 & 6 & 4 & 47.0 & Radiolarian ooze & 0.1 & 0.20 & 0.0 \\
\hline 66.1 & 6 & 5 & 27.0 & Radiolarian ooze & 0.1 & 0.24 & 0.0 \\
\hline 66.1 & 6 & 6 & 75.0 & Radiolarian ooze & 0.2 & 0.21 & 0.0 \\
\hline 66.1 & 7 & 1 & 20.0 & Radiolarian ooze & 0.2 & 0.22 & 0.0 \\
\hline 66.1 & 7 & 2 & 27.0 & Radiolarian ooze & 0.2 & 0.32 & 0.0 \\
\hline 66.1 & 7 & 3 & 110.0 & Radiolarian ooze & 0.1 & 0.00 & 1.1 \\
\hline 66.1 & 7 & 4 & 40.0 & Radiolarian ooze & 0.1 & 0.17 & 0.0 \\
\hline 66.1 & 7 & 5 & 30.0 & Radiolarian ooze & 0.2 & 0.37 & 0.0 \\
\hline 66.1 & 7 & 6 & 30.0 & Radiolarian ooze & 0.2 & 0.21 & 0.0 \\
\hline
\end{tabular}


TABLE 3 - Continued

\begin{tabular}{cccrlcccc}
\hline Hole & Core & Section & $\begin{array}{c}\text { Top } \\
\text { Interval }\end{array}$ & \multicolumn{1}{c}{ Lithology } & $\begin{array}{c}\text { Total } \\
\text { Carbon } \\
(\% \text { wt. })\end{array}$ & $\begin{array}{c}\text { Organic } \\
\text { Carbon } \\
(\% \text { wt. })\end{array}$ & $\begin{array}{c}\text { Calcium } \\
\text { Carbonate } \\
(\% \text { wt. })\end{array}$ \\
\hline 66.1 & 8 & 1 & 62.0 & Radiolarian ooze & 0.2 & 0.22 & 0.0 \\
66.1 & 8 & 2 & 130.0 & Radiolarian ooze & 0.2 & 0.19 & 0.1 \\
66.1 & 8 & 3 & 30.0 & Radiolarian ooze & 0.2 & 0.24 & 0.0 \\
66.1 & 8 & 6 & 76.0 & Radiolarian ooze & 0.1 & 0.20 & 0.0 \\
\hline
\end{tabular}

to a maximum of over 90 per cent at 560 meters (Early Oligocene).

Organic carbon was detected in about half of the samples processed in amounts up to 0.93 per cent. A sample of Early Oligocene marl at 555 meters contained 0.12 per cent.

\section{Site 64}

The nannofossil ooze-chalk-limestone sequence penetrated at Site 64 contains more carbonate in the upper part than does either Site 62 or Site 63. However, as at the other two sites, carbonate content is lowest in near surface Quaternary materials ( 80 per cent). Carbonate content increases to 90 per cent in Core 64.0-2 and remains reasonably constant through the Middle Eocene chalk at the bottom of the hole ( 970 meters).

Detectable organic carbon is more sparse at Site 64 than at Sites 62 and 63 . Amounts are small $(\leqslant 0.15)$ and confined largely to depths greater than 430 meters (Early Miocene or older).

\section{Site 65}

The Late Eocene-Early Oligocene nannofossil radiolarian ooze and silicified limestone at 110 to 150 meters in Site 65 is relatively rich in carbonate, containing as much as 33.8 per cent. However, the radiolarian ooze section, both that above and below this sequence, contains negligible carbonate throughout $(<5.0$ per cent).

Small amounts $(\leqslant 0.36$ per cent) of detectable organic carbon are present throuthout the section penetrated.

\section{Site 66}

Except for a layer in Section 66.0-2-2 where the carbonate content is 8.4 per cent, the carbonate content of both the radiolarian ooze and the pelagic clay penetrated at Site 66 is nil. Small amounts of organic carbon $(\leqslant 0.35$ per cent) are present throughout the section.

\section{Site 67}

One sample from Section 67.0-1-1 was analyzed. It contained no carbonate and 0.2 per cent organic carbon. 